\title{
Dominant discourses on what it means to be a 'real' man in South Africa: The narratives of adolescent male orphans
}

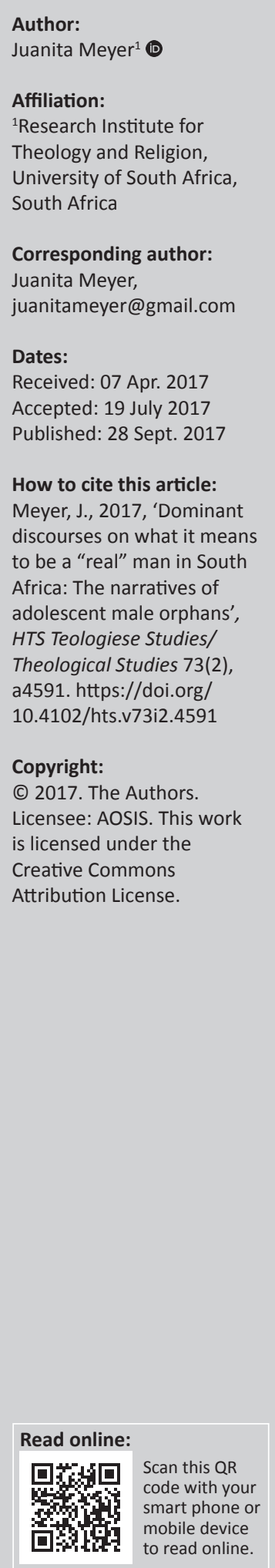

South Africa is known as the rainbow nation because of its variety of culture and religion. In essence South Africa is a spiritual nation, and $85.7 \%$ of her people affiliate to a Christian belief system. Despite this, crimes against women and children run rampant as some traditional male roles advocate patriarchal values that at times negatively affect relations between men and women. This article postulates that specific patriarchal values inform the development of a masculine identity, in spite of the fact that most South African families are headed by female caregivers. At the same time, however, most of these families are affected by extreme poverty and father absence; therefore, many boys are raised without an adequate male role model. This article, emanating from a broader study, explores the relationship between the development of a masculine identity amidst father absence, influenced by rapid colonisation and in the context of a specific religion and culture. It reflects on some of the narratives of the research participants that relates specifically to the theme of 'what it means to be a real man', eliciting the dominant discourses around masculinity and femininity in South Africa, informed by religion, traditional culture and pop culture. This article then postulates that religiosity in South Africa is not removed from the social function and performance of the social constructs of masculinity, cultural values and parental involvement and that these constructs interact with each other in a special way to produce what we come to know as the South African man.

\section{The current situation in South Africa}

Although South Africa is known for its variety in culture and religion, with $85.7 \%$ of her people affiliating to a Christian belief system (cf. StatsSA 2015:2), statistics on violence and crime-specifically crime against women and children - poverty, orphanhood and parental abandonment are dire.

According to the statistics provided by Statistics South Africa (StatsSA 2013:3) women in South Africa - regardless of race or location - are more impoverished than men. Despite this, female-headed households, particularly those in rural areas, are larger and more complex in structure than those headed by men. The large size of households, the fact that more than half of all the households (55.2\%) are headed by women and that women on average earn less than men all contribute to their poverty status.

StatsSA (2013:9) has also found that many children living within traditional female-headed households are not biologically related to their mothers. This concurs with the statistics that $37.8 \%$ of all children live with their mother only, while 3.2\% of children live with their father only. A shocking $22.0 \%$ of all children live with neither biological parent (StatsSA 2013:55). It has also been found that children in South Africa are on average poorer than any adult population. Children who live with their mothers only are the worst struck by poverty, estimating that $71.3 \%$ of these children live under the upper-bound poverty line. This indicates that father absence impacts greatly on the poverty status of a child (StatsSA 2013:56).

To further complicate matters, it is estimated that approximately one in five-3.8 million - children are orphaned in South Africa. Of these an estimated 2.3 million are paternal orphans, 700000 maternal orphans, and because of the reduced presence of fathers at homes, $3 \%$ of these children have an unknown orphan status (cf. StatsSA 2013:57). UNICEF (n.d.a) estimates that approximately 150000 children are living in child-headed households. 
Child Welfare South Africa estimates that more than 3500 babies were abandoned in South Africa in 2010, of which only 1699 were adopted by 2013. Causes of child abandonment are numerous and diverse, ranging from inadequate governmental legislation, to issues pertaining to poverty and gender-based violence (cf. Blackie 2014:1-3).

As to be expected, the loss or abandonment of one or both parents results in the loss of much needed protection and adult guidance. These children are more likely to become impoverished, to be abused and exploited and to be marginalised from essential services such as health, education and social justice services (cf. UNICEF n.d.a).

Violent crime has been sustained in South Africa over the past 20 years (cf. Bothma 2015), hampering the realisation of people's access to basic human rights. As such, murder has increased from 2014 to 2015 by 4.6\%, bringing the number of annual murders for 2015 to 129045 (cf. Bothma 2015). UNICEF South Africa (n.d.b) states that an estimated one woman or child in every 833 people is raped (these are only reported numbers). It is known that women who are raped generally experience domestic violence at the hands of their partners or husbands. Children are therefore equally at risk, as child abuse correlates positively with domestic violence. As a result of the high rates of sexual violence and coercion, South Africa has one of the highest rates of teenage pregnancy in the world. Sexual violence and coercion are exacerbated by our high levels of poverty, drug and alcohol abuse and peer pressure (Blackie 2014:5).

\section{So what do these have to do with men?}

At the backdrop of this dire situation lays the myriad discourses disseminated between male and female role players regarding what it means to be a man and what it means to be a woman. These discourses on masculinity and femininity are powerful in their influence on the behaviour of both men and women, as it lays the foundation for the development of an identity that informs a person on how to be male and female in this world. This article is specifically interested in the dominant discourses disseminated between boys and men in South Africa that informs the development of a specific gender identity which operates at the expense of the psychological and physical welfare of girls and women.

Therefore, this article narrates collected discourses from a handful of teenage boys, on how they understand manhood, masculinity and what a 'real' man is. It provides valuable, albeit modest, insights into the world and the experiences of young South African men.

\section{Background to the larger study}

Narratives around masculinity and manhood were collected from a case study sample of seven adolescent boys, from 2007 to 2010. These participants were selected according to nonprobability sampling methods. Six of the boys had lost their mothers to death, at least 4 years prior to this study. Five of the boys were abandoned by their fathers and two boys (twins) have lost their fathers during a gun-fighting incident when they were toddlers. Subsequently, all the boys, except one, are double orphans. At the time of the study all the boys lived in conditions of extreme poverty and were registered with several non-profit organisations for the 'orphaned and vulnerable'. Some of the boys resided in a safe house of one of these organisations, while the remaining boys received material support from their organisations.

${ }^{1}$ Open-ended, unstructured and semi-structured interviews were conducted during a weekend breakaway to Magaliesburg, Sikelele Camp Site, 26-28 February 2010 with all of the boys, within focus-group sessions.

\section{Theoretical viewpoints}

\section{The postfoundational notion of practical theology and social constructionism}

The research's epistemology and methodology follow the paradigm of a postfoundational notion of practical theology. Practical theological inquiry - according to Gerkin (1991:13) - is concerned with both theological and practical considerations. As practical theologians we are interested in serving people and their concerns through their daily communications and relations within a specific cultural and social setting, by showing continuity between the story of the Bible and the story of the particular person at a particular place within a particular point in time. Practical theology, therefore, aims at addressing specific social issues and challenges from the foundations of scripture, emphasising the imperative of action; hence, it is the logos through, within and by praxis. The result is that practical theology is propelled by elements of liberation, justice and reinstating human dignity.

Central to the practice of practical theology is a thorough understanding of a specific context, emanating from the contextual imperative of practical theology. Accordingly, Müller (2005:78) states that practical theology is indeed, '... only possible as contextual Practical Theology', as its focus should always be on specific, localised and concrete contexts, driven by the lyrics of locality, embeddedness and situatedness. As a result, practical theology is practised through the '... reflection on practice from the perspective of the experience of the presence of God' (Müller 2005:73).

The epistemologies of social constructionism and postfoundationalism add to the value that practical theology can add to the study of specific contexts, from the perspective of the experience of God, in several ways.

The model of transversality within the broader paradigm of postfoundationalism holds that we relate to our world only through interpreted experiences (van Huyssteen 1999:138), and that diverse disciplines can offer valuable alternative interpretations of our experiences (cf. Müller 2003:299), as 1.Permission was obtained from the participants to publish their narratives. 
interpretations inevitably differ. In a similar manner social constructionism holds that all experiences and realities are embedded in a specific, local context and informed by various traditions, which influence the subjective interpretation of individual experiences. Therefore, an individual's interpretations and identity is in essence constructed by personal, cultural and historical factors.

Both postfoundationalism and social constructionism convey the idea of 'received' interpretations, which implies that interpretations and understandings are received through various traditions and socio-cultural discourses. Postfoundationalism emphasises the importance of crosscultural and interdisciplinary conversation, which will inquire into the different constructed interpretations of similar experiences. Social constructionism similarly emphasises the role of context and traditions in shaping the understanding and meaning-making process of the individual. Therefore, collectively these two paradigms suggest that interpretations are not constructed individually and in isolation, but is in essence co-constructed and received through the various constructs provided by the wider socio-cultural and traditional discourses. Subsequently for a practical theologian to develop a clear understanding of experiences, he or she needs to move beyond one's own discipline and context, in search for various interpretations that can add value to the meaning-making process (cf. Alvesson \& Sköldberg 2000:17; Müller 2003:299300). What makes those insights of postfoundationalism especially valuable is that it does not view varying socially constructed interpretations from different disciplines as conflicting, but instead embraces it as various possible interpretations that complements the creation of a holistic indepth understanding of each and every individual experience (cf. Müller 2003:299).

Furthermore, both postfoundationalism and social constructionism emphasise the importance of language and its performative function in conveying discourses and transformation. Van Huyssteen (2006:21) states that patterns of discourse and action are embedded and conveyed through the praxis of communication and conversation. Language is integral, not only in the transformation and re-construction of socially constructed narratives, but it is also the vehicle through which interdisciplinary and cross-contextual conversations take place. Language, then, contains the notion of possibilities.

According to these two epistemologies, local contexts are embedded in the construction of interpretations. Therefore, as van Huyssteen (1999:113) states, our rational reflections are embedded in the context of living and evolving and developing traditions. Before a practical theologian can move beyond the boundaries of his or her episteme and enter the realm of interdisciplinary and cross-co contextual conversation, this embeddedness should be acknowledged as the source of our beliefs and actions (cf. van Huyssteen 2006:25).

Similarly, social constructionism states that our identity and resources for adding meaning to our narratives are embedded in specific socio-cultural and historic contexts, and that this embeddedness impacts on the construction of the selfnarrative. This has real consequences for both the author of a narrative and the practical theologian whose task is to interpret these narratives in reflection to the author's experiences of God. Müller (2003:299-300) confirms, however, that the practical theologian is liberated by the idea that identity and rationality is socially constructed as he or she is freed from the urge to defend his or her rationality over other more accepted universal, empirical, modernist rationalities. Once freed from this notion, the practical theologian can engage in true interdisciplinary dialogue in an attempt to understand the experiences of people in a manner more congruent to the various realities that a person might come to face.

Therefore, by adding the notion of a postfoundational rationality to the practice of practical theology, and subsequently incorporating the model of transversal reasoning, the praxis of practical theology ensures that both reflection and continuous evaluation of episteme remains the imperative of practical theology. Müller (2005:80) postulates that a postfoundational notion of rationality positions practical theology within a theological world as it takes the movement of practice-theory-practice seriously (cf. Müller 2005:80; van Huyssteen 1997:180-192). Therefore, a postfoundational notion of practical theology provides the field with an integrative narrative, which includes the theologian in both processes of 'story-telling' and 'storymaking'. The practical theologian should however be acutely sensitive and descriptive in the deconstruction of problematic discourses, and in his or her development of alternative discourses or narratives, by also embodying an attitude of sensitivity, discretion, heightened awareness of biases and being open to the context while listening for cues of dominant discourses (cf. Müller 2005:86).

\section{The metaphor of narrative ${ }^{2}$}

Social constructionism proposed the idea that narratives can function as a frame of reference in organising one's experiences and understandings. Ricoeur (1976) states that narratives can assist in both the creation and the transformation of identity through the manner in which facts and events are selected and linked (cf. Demasure \& Müller 2006:412). The author of these narratives is then presented with many possibilities in the construction of a narrative. Nevertheless, the selection process of facts and events happens by chance and not because it is the only way that these facts and events can be selected and connected - the content of a narrative is therefore not arranged as a cul de sac (cf. Demasure \& Müller 2006:412).

Narratives are constructed. Even though people construct stories about themselves and their experiences that reflect the meaning they attach to these experiences, these stories still reflect the dominant discourses of a society or social group. Thus, when a narrative is told, multiple dimensions of 2.Ideas articulated in this section follow similar lines of thought as proposed in a former article written by the author (cf. Loubser \& Muller 2011). 
influence are unveiled. Demasure and Müller (2006:412) state that narratives reveal much more than just concepts - it contains the life story of a person and when an inquiry is made about a person that life story is put on the centre stage. The result is that each person has a narrative identity, which serves as a resource centre for understanding past events and experiences, and in the creation of future narratives. A narrative identity, however, is not only created by an individual, but also by a social group. Various people interact in the co-construction of a narrative identity, through the vehicle of dialect which transports symbols and metaphors inherent in text to the linguistic activities of people (cf. Demasure \& Müller 2006:412).

Another characteristic of narratives is that it is shared. The sharing of narratives creates an opportunity for the reader to identify with the characters of the story - through the recollection of images and feelings - thereby engaging every person in the audience (cf. Gergen 1999:158-159; Müller \& Demasure 2006:415). The audience, when listening to a story, will then either celebrate or suffer with the character: imagining themselves in the position of the character(s), thereby experiencing something from the perspective of the author. As soon as different perspectives are experienced and appreciated, agreement becomes possible and the possibility of resistance is limited (cf. Demasure \& Müller 2006:415). Ultimately, then, the telling and the sharing of stories open up various possibilities of meaning-making, as people realise that many characters contribute to the construction of a story, and that a story can be told and retold in many different ways. People are therefore not bound by the idea that only one interpretation is possible and that their thoughts and actions must be directed by this universally accepted notion of meaning and purpose. They realise that they have the freedom in constructing and transforming previous hopeless narratives into narratives that contain the possibilities of multiple meanings. Constructed identities are now liberated as people realise that transformation through alternative narratives is not only possible, but even acceptable, and more so, desirable.

\section{Masculinity and identity in the South African context}

Masculinity in South Africa is complicated. In South Africa the development of a social identity is complicated by the continuous process of transformation of a socio-cultural identity. This is not the ideal and might hamper the development of both an individual and socio-cultural identity (Thom \& Coetzee 2004:184).

The complexities in the development of a social identity is referred to as intersectionality (Crenshaw 1991:1299), which acknowledges the construction of identities through the '... intersection of multiple dimensions'. Intersectionality focuses on the framing of social identities to include the construction of identity by social institutions, history and place (Moolman 2013:94).
Moolman (2013:94) postulates that the intersectionality of identities is shaped by various social and political changes of the time implying that at times constructs of, for instance, race might become more significant and relevant than, for example, religion or gender. This implies that intersectionality contains various trajectories of relationality, which results in different forms and functions of power.

There are multiple definitions for the concept of 'masculinity', but is in my mind most adequately defined by Moolman (2013:95) as '... the multiple, shifting, fluid practices, and performances of gendered bodies and identities' (cf. Mama 1995). Moolman (2013:95) suggests that 'masculinity' stands in relation, and at the same time, in opposition to the concept of 'femininity' and is largely organised through ideological discourses, but is not always attached to the male body (cf. Amadiume 1987).

In turn, African masculinities are produced and constituted as a relation of hierarchy, which is established dually by African femininity and western masculinities. This implies that masculinity then becomes hegemonic - a dominant form of masculinity in a particular society, which gives power and privilege to the men who fit into this box (cf. Morrell 1998:608).

This definition of hegemonic masculinities provides a frame of reference for understanding the experiences and perceptions of South African men, in relation to various ideological constructs, precisely because it helps us to understand how power is mobilised in producing violence. Therefore, African masculinities are a complex matrix of relations of power; accordingly, Moolman (2013) states:

Power, privilege, and protection as constitutive of hegemonic masculinity are achieved through different vehicles and mechanisms, depending on race, class, age, geography, and context. In Africa, the power and privilege of hegemonic masculinity are legitimized through the simultaneous existence of a dual ideological space, modernity and its binary, tradition, often coexist. (p. 96)

These complexities should therefore be kept in mind when reading the remainder of the article, which will narrate some of the participants' experiences and opinions regarding masculinity, manhood and what it means to be a 'real' man.

\section{Money and work}

'Money makes a man, and gives a man, power'. This is a statement made by one of the participants of this research (Kgotoso 2010). This is a powerful statement, supported by the other participants and discourse regarding the man as the 'breadwinner'. This participant elaborated by saying that if a woman has money; she will not be in need of a man. He says: 'Money gives her wings', implying that she will be free of a man's power and control.

Similarly, Morrell (2006:20) reports that in several part of Africa, a man receives respect if he is able to provide 
materially for his family. In these cases, the person will be viewed as 'the man of the house'.

Accordingly, all the participants are in agreement that it is a man's responsibility to provide financially for his family, as this affirms his masculinity or manhood. It is interesting to note that some of the female participants supported this idea as well.

Embedded in this discourse is not only an altruistic need to care for one's family, but also the need to gain and regain power and control through one's earnings. As an example, the twins of this study stated that they feel unimportant and 'small' in the presence of wealthy men. It seems that wealthy men in South Africa affirm their wealth through their 'acquisition' of young pretty women.

The participants said that older wealthy men will 'take' their women because they have more power through their wealth. Money and women are then placed alongside each other, as property for men to gain in their competition with each other. Research conducted by Ragnarsson et al. (2010) confirms money and women as symbols of material wealth and says:

Besides displays of overt economic status, a player would be expected to show he could afford and handle several women at the same time. Women were identified as a key attribute of the dominant masculine ideal. Having multiple, often young female sexual partners further enhanced men's social position and women served as a marker of both sexual and financial power. (p. 4)

Similarly, the participants affirm that the type of occupation a man employs determines his status in the community, although they agree that one's employment is only a means to an end - to gain wealth, and therefore power. Of more importance however, is that the occupation of the man is regarded as more important than the position that their female partner occupies in a workplace. Again the discourse of power over women, and other men (the idea of hegemonic masculinity), through one's income prevails.

\section{Fatherhood}

It became evident through the narratives of the participants that being a 'real' man and being a 'good' man are strongly related to the concept of fatherhood. Two roles of fatherhood surfaced through their narratives: providing guidance to one's children and providing for their financial needs.

The first imperative of fatherhood is supported by the narratives of Manqoba, where he expresses his longing for his father's emotional and psychological involvement in his life, despite the fact that he provided in his material needs. According to the participants, tending to a child's needs for nurture, love and care provides a child with a sense of stability and outweighs any financial needs a child might have. At the same time, one of the participants, Molimi, stated that negative 'parental' presence could do more harm than good.
Kgotoso and Manqoba - two of the participants - voiced their concerns regarding the promiscuity they witness from married men, or men in long-term relationships. They are of the opinion that men face many temptations, and as a result of lacking proper male guidance, men give into these temptations and use and abuse the women in their lives. In essence, Manqoba believes that one of the best contributions a father can make is to teach his son(s) how to take ownership of their responsibilities. Kgotoso perceives this through a religious lens and states that in his opinion men have moved away from God's instructions.

Most of the participants stated that poverty plays a role in men's resistance to take responsibility for their children and partner. They hold that many men do not have the finances to pay lobola when they want to get married; to pay damages if they impregnate a woman out of wedlock; or to contribute towards maintenance fees, when they are not living with the family.

However, despite this, all the participants stated that one does not need money to be a good father, and at the same time, one does not need to be married to the mother before one takes on the role of a father.

It is interesting to note that more than $70 \%$ of young South Africans, across race, gender and culture, stated in a national survey that parenthood is one of the top four defining features of adulthood. This includes the following imperatives of parents: supporting one's family; safeguarding one's family; caring for the children; and running the household (cf. study conducted by Emmett et al. 2004, in Richter \& Morrell 2006:5).

It is therefore safe to conclude that South Africans are still concerned about the welfare of the family unit and regard it as a life phase to successfully resolve in being an adult. What is even more striking is that many men desire fatherhood and even more so aim to be a good father. They associate being a good father with being a good man (cf. Richter \& Morrell 2006:5).

Despite these statements, absent fatherhood is on the increase in South Africa (Holborn \& Eddy 2011:4), and many fathers neglect their financial and paternal responsibilities (Richter and Morrell 2006:5-6).

Things changed with the coming of the twentieth century and rapid colonisation, as rural production declined and men were forced to seek employment, often, far away from their homes. The concept of fatherhood moved away from the social aspect and emphasised and favoured the financial responsibility of the biological father. It became increasingly difficult and sometimes impossible to maintain an intimate emotional relationship with their children. Morrell (2006:20), however, stresses that in poor communities where resources are limited, good fatherhood might re-emphasise the provident aspect of fatherhood, which is driven by the imperative of securing life opportunities for his children. 
Morrell (2006:15) postulates that the concept of fatherhood is explicitly associated with manhood, although the route to such is not always clear. In many cases, younger men aspire to manhood much earlier than older men are willing to permit. In many societies, however, it seems that the concept of masculinity is inherent in the constructs of fatherhood, being a husband and therefore the 'head' of the home. The concept of hegemonic masculinity seems to prevail in many families, as the power of the father, in some cases, operates to the detriment of women in the house (cf. Morrell 2006:17).

I postulate that in many families in South Africa, a fusion between the traditional and the so-called 'modern' models of fatherhood takes place, where many fathers who are physically present are still seen as the authoritarian figure who demands respect because of his financial providence to the family; however, despite this he might be very domesticated, engaging in a caring, loving and educational manner with his children. However, engrained in this statement is the operation of his sense of hegemonic masculinity, where he determines the roles that he is willing to perform, e.g. there is still a great sense of power and authority, albeit the need to be domestically involved), What is of importance here is that the role occupied is chosen by him, and not demanded by the subordinates of the family.

\section{Protection and responsibility}

Protection, responsibility and accountability were themes commonly mentioned as part of the discourse on manhood and masculinity. Protection seems to be embodied through the conceptualisation of manhood; protection is both an entitlement and a bestowment, by virtue of being a man: bestowment - indicating that a man honours someone or something with his protection; but at the same time an entitlement - because he is a man he protects that which he owns - means that anything and anyone can be owned. For example, the participants in this study stated that because the man is the 'head' of the family, because he is physically endowed to be able to protect and because he respects that which is 'his', he is responsible for providing his protection.

The word 'respect' is often used together with 'protection', albeit laden with subtle forms of power. Kgotoso, for example, says that because a man respects women, he should protect her. Men should also respect other men's property (including their women): '... he should not "take" what is not his' (Tree of Life Camp Sikelelele 2010).

From the participants' narratives, it became clear that one's 'masculinity' should also be protected. Molimi says that that a man should protect his self-confidence, respect and sense of responsibility, if he wants to be seen as the 'head' of the house or family.

The second predominant theme was that of taking responsibility and being accountable for one's actions. Molimi says that a 'real' man is someone who is honest, caring and supportive, in control of his behaviour and who takes responsibility for his actions. Furthermore, a man should be accountable for his mistakes, despite the possibility of punishment. Being accountable is evaluated as more desirable than being responsible.

A final remark on the participants' narratives on this discourse is the conditionality attached to a man's sense of responsibility towards his family. It seems that the concept of responsibility relates positively with the concept of respect. One of the participants stated that a man should be responsible for tending to the needs of his family, if the members of this family show him respect.

\section{Power and demanding respect}

Power and respect were often voiced as virtues of being a great man. As seen previously, respect is often the consequence of being a good and responsible man. The participants unanimously stated that men need to feel both powerful and respected.

Mpho equates a 'great' man to power, and a 'great' woman to integrity. There seems to be a positive correlation between a man's sense of power and his social status (respect) and wealth enjoyed in the community. Money is seen as the means to power, and power in turn grants one control over women, over peers and respect from the community. Once a person is granted power, respect - according to the participants - will follow naturally.

Even today, young men understand that being initiated into manhood means that certain rights are conferred upon them, which results in them being respected (cf. Morrell 2006:16). In pre-colonial and early colonial periods, fathers are remembered as authoritarian figures and named 'baba', who - from their status as fathers and husbands - demanded respect (cf. Hunter 2006:101).

It became evident through the narratives of the co-researchers that particularly women play a role in either confirming or disconfirming a man's sense of masculinity. Molimi states that he would like to marry a woman who will 'reflect' who he is as a man. This seems to indicate that a women and her happiness is a reflection of the competency of her partner in making her happy. In explaining, Molimi says that while a 'real' man must be a family man, he must also be 'satisfied in all ways', perhaps indicating the reciprocal relationship between a man's sense of responsibility, and the satisfaction of his needs.

Both Kgotoso and Molimi implicitly stated that a man's masculinity is affirmed by the respect that 'his' woman has for him, and when he is liked and loved by his family. Kgotoso specifically said that it is the woman's responsibility to take care of him (cooking, cleaning, etc.), to be committed to, and honest with him. These actions will affirm his manhood. 


\section{Violence}

Violence is something experienced by all the participants. Some of them suffered at the hands of a violent brother, father or mother's boyfriend; others witnessed how their loved ones were assaulted and abused.

All the participants agreed that a 'real' man will not participate in violent behaviour, but they admitted that men tend to lose control over their desires and aggressive tendencies. However, in their opinion a man needs a male role model to teach a boy what is acceptable and unacceptable behaviour.

This corresponds to research conducted by Wilson (2006:32) who found that a great proportion of children living in poor households where the biological father is absent have experienced violence at the hands of a stepfather or the mother's boyfriend. In research conducted by Gibbs et al. (2014:120) with young men in a township in KwaZulu-Natal, they found that participants justified their use of violence as a response to several actions of women which might affect their dignity and sense of respect. Some of these included the fear that a woman might have an affair, or that a woman might acquire a job that would give them economic freedom. Men would therefore use violence to reassert their dignity.

Gibbs et al. (2014) also found that men readily defend their honour through violence towards other men. They state:

Men's violence to one another was very public and linked closely to men's overarching concern to position themselves within a dominant gendered hierarchy. While alcohol often fuelled this violence, men felt they could not 'back down' without losing respect. (p. 121)

There are several explanations brought forth for the prevalent use of violence in South Africa, one being that historically the use of violence has been legitimised institutionally by accepting that both black and white men legitimise their use of violence as part of a gendered practice within their culture (cf. Morrell, Jewkes \& Lindegger 2012:20). The former context of South Africa was unique in its construction of black masculinities. Hunter (2010) postulates that in the 1970s and 1980s, during industrialisation, black men were forced into the working class, and as such respect was gained only to the extent to which he can provide financially and create a home for his family. In addition to this, male power was gained by having control over one's wife and children. This created a new hegemonic masculinity for black South African men (Gibbs et al. 2014:116).

Seedat et al. (2009:978) side with Hunter (2010) and add that negative sources of power are available to young black men as a result of many years' economic, political and social exclusion and the inter-generational violence they had to endure at the hands of conservative white patriarchies (Gibbs et al. 2014:122). Other researchers explain men's tendency towards violence as resulting from harsh childhood experiences which, as a result, reduce men's empathy and feelings of guilt. Therefore, certain behaviours, such as the tendency to engage in risky behaviours and acting violent, have already been set up in their childhood psychology and then enabled through adult practices such as patriarchy (cf. Gibbs, et al. 2014:116; Mathews, Jewkes \& Abrahams 2011:960).

Looking at this phenomenon from a different perspective, Hunter (2006:99) argues that notions of male power, such as the use of violence against women and children, might result from the opposite - that is because men are disempowered by socioeconomic factors, they might engage in violent behaviour to regain such notions of power (cf. Silberschmidt 2001:658). The research of Wood and Jewkes conducted in the eastern Cape in 2011 supports that young men - often economically marginalised - resort to violence in controlling their female partner(s). Hunter's (2010) work emphasises the ability of young marginalised men to 'negotiate the tension between expected roles as providers in romantic relationships and their lack of economic power through subtle negotiations and an emphasised heterosexuality' (Gibbs et al. 2014: 116-117).

\section{Being publicly religious and emotional}

The co-researchers said that although they would like to share their views on their religion or on God, the reality is that a man is seen as 'weak' by his community when doing so. Similarly, being open about one's beliefs and values is equated with being 'feminine', and as a result, being seen as feminine is most feared by many men. The co-researchers agree that in their community a man is seen as 'weak' if he expresses his feelings, or if he is over-emotional.

Research confirms the view that religiosity is seen as a feminine quality. Although no African research has been conducted on this topic to date, Euro-American research has found that men participate less in religious rituals and worship activities; if they do attend church, it is for different reasons than for women; they proclaim less often and less devout beliefs; and state more often that faith is not essential to their daily functioning (cf. Thompson \& Remmes 2002:521).

In relation to this, several scholars attempt an explanation of the reasons behind men in general, appearing less religious than women. This article does not permit a discussion on these theories; however, what is of importance though is what these theories tell us about the social construction around expression of religiosity.

I argue that the expression of one's religiosity or spirituality depends on one's community, culture and specific peer group. These groups will legitimise (or not) the male expression of religiosity. Therefore, the expression of religiosity depends much on these groups' understanding of masculinity and femininity and what is acceptable and permissible religious behaviour for each. 


\section{Sexual issues}

Kgotoso and Molimi agree that having sex confirms one's manhood and masculinity. They say that it is accepted in their community that a boy will prove his manhood by engaging in sexual relations with not only one, but many women or girls. Therefore, men are encouraged to have multiple sexual partners and mainly gain respect for doing so. Kgotoso (2010) stated that he appreciates sex from a girl although he does not necessarily love her. The participants also said that 'having fun' is an additional reason to engage in sexual activities. All the participants also believe that men are not in control of their sexual desires - rather, they are victims of their biology which overwhelms them with sexual urges which they cannot resist.

Research from other scholars in South Africa confirms these findings such as Ragnarsson et al.'s (2010:4) research, which shows that young males in peri-urban areas of South Africa regain power by seeking multiple sexual partners in establishing their masculinity amongst peers. In another research study a 12-year-old boy was asked what he understands as being a man. He replied '... to have sex with women' (NPPHCN 1995:35).

Gibbs et al. (2014:119) have found that men's sense of masculinity and power is rooted in their heterosexuality and violence. In turn, Gqola (2009) reminds us in a Mail and Guardian article that it is not only young men who engage in and justify multiple sexual partners, but adult men also justify such behaviour with the use of cultural tradition. As an example the practice of virgin testing comes to mind, which is in essence a patriarchal practice of power which communicates to the youth and especially to young men that women's sexuality should be monitored and controlled, while men are not in control of their sexual urges and activities and are therefore entitled to have sex.

It is interesting to note that Morrell (2006:17) has found that the performance of masculinity for boys and young men from poor backgrounds depends much more on heterosexual success and activities than for boys from wealthy or middle class homes. This highlights then the loss of a sense of power for boys and men from poor socioeconomic backgrounds, and how much power is entailed in economic wealth.

\section{Conclusion: What does it mean to be a real man in South Africa?}

It is clear that manhood is something aspired to by many boys, not only physically, but more so psycho-socially (Morrell 2006:16). Reasons for this might include the freedom associated with this, but more likely is the power and respects conferred with it by the community and amongst one's peers. As such, manhood is dependent on the degree to which adult men socially accept a boy - as a man - into the community. Therefore, manhood is prioritised by culture and promoted through the community (cf. Morrell 2006:16) and its ideology around the concepts of masculinity and femininity. This status, however, does not go without responsibilities. Much pressure is asserted onto men to not only be a man, but also a 'good' man. It has been seen, however, that we can distinguish between a 'good' man and a 'real' man and that these concepts aren't necessarily mutually exclusive.

Once confirmed as a 'man', a young man needs to engage in a series of behaviours that will maintain a certain status of his manhood. The chosen behaviours will be largely determined by the context in which such transition and transactions take place. A boy's family, culture, religion, peer group and sociopolitical context determine the operationalisation of his manhood. As a result of unequal power distribution between men, women, children and other male sexualities, manhood and heterosexual masculinities became a much-contested concept and as Richter and Morrell (2006:7) state: masculinity finds itself in a crisis.

Today masculinity is confronted with discourses that question traditional male entitlement and the power it exerts; simultaneously, women are empowered to explore avenues previously only reserved for men. In interpreting these narratives, I argue that the development of South African men's masculinity was halted by the socio-political context of colonisation and Apartheid, and as a result, the South African man finds himself caught up in the web of the developed world's modern and western concepts of masculinity (which was already contested 50 years or so ago in the western developed world) and the memory of fighting for a rightful place in their homes as the man of the house during a time when they were dominated by white hegemonic masculinity. What complicates the matter even more is that because of the high rates of unemployment and poverty in present day South Africa, a great deal of South African men are robbed of the opportunity to contribute positively, and equally to the grand gender narrative.

Men are battling. They are battling for their honour and their pride. They are battling for their rightful place in their homes and in the workforce. While the global first world is talking equality, liberation and empowerment, South African men struggle to find their equal place in a post-modern, postcolonial, post-Apartheid world, without the use of something they have come to know so well - power.

The picture, however, is not only sombre. These narratives also tell a tale of longing and change: a longing to give and receive unconditional love and acceptance; a longing for the expression of their unique talents and skills; and a longing for security and stability experienced in the safe haven of a family unit. Inevitably such longings will motivate change and men will find their place in their family homes once again and take up their responsibilities with eagerness. Abraham Maslow said: 'What is necessary to change a person is to change his awareness of himself' (Stephens 1972:21). 


\section{Acknowledgements Competing interests}

The author declares that she has no financial or personal relationships which may have inappropriately influenced her in writing this article.

\section{References}

Alvesson, M. \& Sköldberg, K., 2000, Reflexive methodology: New vistas for qualitative research, London, Sage.

Amadiume, I., 1987, Male daughters, female husbands, Zed Books, London.

Blackie, D., 2014, 'Fact sheet on child abandonment research in South Africa', in National Adoption Coalition, viewed 10 October 2016, from http://www. adoptioncoalitionsa.org/wp-content/uploads/2014/05/Fact-Sheet-Research-onChild-Abandonment-in-South-Africa_Final2.pdf

Bothma, N., 2015, 'Factsheet: South Africa's 2014/15 murder and robbery crime statistics', in The Daily Maverick, viewed 15 October 2016, from http://www. dailymaverick.co.za/article/2015-09-29-factsheet-south-africas-201415-murderand-robbery-crime-statistics/\#.VIQUmnYrlgs

Crenshaw, K., 1991, 'Mapping the margins: Intersectionality, identity politics and violence against women of color', Stanford Law Review 43(6), 1241-1299. https:// doi.org/10.2307/1229039

Demasure, K. \& Müller, J.C., 2006, 'Perspectives in support of the narrative turn in Pastoral care', Ned. Geref. Teologiese Tydskrif (NGTT) 47(3), 410-419.

Emmett, T., Richter, L., Makiwane, M., du Toit, R., Brookes, H., Potgieter, C. et al., 2004, The status of youth report 2003, Umsobomvu Youth Fund, Johannesburg.

Gergen, K., 1999, An invitation to social construction, Sage, London.

Gerkin, C.V., 1991, Prophetic Pastoral practice, Abingdon Press, Nashville, TN.

Gibbs, A., Sikweyiya, Y. \& Jewkes, R., 2014, “'Men value their dignity”: Securing respect and identity construction in urban informal settlements in South Africa', Global Health Action 7(1), 23676. https://doi.org/10.3402/gha.v7.23676

Gqola, P.D., 2009, 'Pressure to be promiscuous', Mail and Guardian online, viewed 09 March 2016, from http://mg.co.za/article/2009-02-11-pressure-to-bepromiscuous

Holborn, L. \& Eddy, G., 2011, 'First steps to healing the South African family', in The South African Institute of Race Relations, viewed 15 September 2016, from http://
irr.org.za/reports-and-publications/occasional-reports/first-steps-to-healing-theirr.org.za/reports-and-p
south-african-family

Hunter, M., 2006, 'Fathers without amandla: Zulu-speaking men and fatherhood', in L. Richter \& R. Morrell (eds.), Baba: Men and fatherhood in South Africa, pp. 99-107, Human Science Research Council, Pretoria.

Hunter, M., 2010, Love in the time of AIDs: Inequalities, gender and rights in South Africa, Indiana University Press, Bloomington, IN.

Loubser, J. \& Muller, J.C., 2011, 'The use of metaphors in narrative research in exploring and describing experiences of adolescent male orphans affected by HIV and AIDS', HTS Teologiese Studies/Theological Studies 67(2), Art.\#1009, $1-9$.

Mama, A., 1995, Beyond the masks: Race, gender and subjectivity, Routledge, London.

Mathews, S., Jewkes, R. \& Abrahams, N., 2011, 'I had a hard life': Exploring childhood adversity in the shaping of masculinities among men who killed an intimate partner in South Africa', British Journal Criminology 51(6), 960-977. https://doi. org/10.1093/bjc/azr051

Moolman, B., 2013, 'Rethinking masculinities in transition', South Africa. African Identities 11(1), 93-105. https://doi.org/10.1080/14725843.2013.775843
Morrell, R., 1998, 'Of boys and men: Masculinity and gender in Southern African studies', Journal of Southern African Studies 24(4), 605-630. https://doi. org/10.1080/03057079808708593

Morrell, R., 2006, 'Fathers, fatherhood and masculinity in South Africa', in L. Richter \& R. Morrell (eds.), Baba: Men and fatherhood in South Africa, pp. 13-25, Human Science Research Council, Pretoria.

Morrell, R., Jewkes, R. \& Lindegger, G., 2012, 'Hegemonic masculinity/masculinities in South Africa: Culture, power, and gender politics', Men and Masculinities 15(1), 11-30. https://doi.org/10.1177/1097184X12438001

Müller, J.C., 2003, 'HIV/AIDS, narrative practical theology, and postfoundationalism: The emergence of a new story', Hervormde Teologiese Studies 60(1/2), 293-306.

Müller, J.C., 2005, 'A postfoundationalist, HIV-positive practical theology', Practical Theology in South Africa 20(2), 72-88.

National Progressive Primary Health Care Network (NPPHCN), 1995, Youth speak out for a healthy future: A study on youth sexuality, NPPHCN/UNICEF, Braamfontein.

Ragnarsson, A., Townsend, L., Ekstrom, A., Chopra, M. \& Thorson, A., 2010, 'The construction of an idealised urban masculinity among men with concurrent sexual partners in a South African Township', Global Health Action 3(1), Art \# 5092 https://doi.org/10.3402/gha.v3i0.5092

Richter, L. \& Morrell, R., 2006, Baba: Men and fatherhood in South Africa, Human Science Research Council, Pretoria.

Ricoeur, P., 1976, Interpretation theory, discourse and the surplus of meaning, Texas Christian University Press, Fort Worth, TX.

Seedat, M., Van Niekerk, A., Jewkes, R., Suffla, S. \& Ratele, K., 2009, 'Violence and injuries in South Africa: Prioritising an agenda for prevention', Lancet 374(9694), 1011-1022. https://doi.org/10.1016/S0140-6736(09)60948-X

Silberschmidt, M., 2001, 'Disempowerment of men in rural and urban East Africa: Implications for male identity and sexual behavior', World Development 29(4), 657-671. https://doi.org/10.1016/S0305-750X(00)00122-4

Statistics South Africa (StatsSA), 2013, Men, women and children: Findings of the living conditions Survey 2008/2009, viewed 15 October 2015, from http://www. statssa.gov.za/publications/Report-03-10-02/Report-03-10-022009.pdf

Statistics South Africa (StatsSA), 2015, General Household Survey P0318, viewed 15 October 2016, from https://www.statssa.gov.za/publications/P0318/ P03182015.pdf

Stephens, W.M., 1972, Life in the open sea, McGraw-Hill, New York.

Thom, D.P. \& Coetzee, C.H., 2004, 'Identity development of South African adolescents in a democratic society', Society in Transition 35(1), 183-193. https://doi.org/10. 1080/21528586.2004.10419113

Thompson, E.H. \& Remmes, K., 2002, 'Does masculinity thwart being religious? An examination of older men's religiousness', Journal for the Scientific Study of Religion 41(3), 521-532. https://doi.org/10.1111/1468-5906.00135

Tree of Life Camp, 10-12 October 2008, Sikelelele, Magaliesberg.

Tree of Life Camp, 26-28 February 2010, Sikelelele, Magaliesberg.

UNICEF, n.d.a, Orphans and vulnerable children, viewed 10 October 2016, from https://www.unicef.org/southafrica/protection_6631.htm

UNICEF, n.d.b, Protection from violence and abuse, viewed 10 October 2010, from https://www.unicef.org/southafrica/protection_4711.html

Van Huyssteen, J.W., 1997, Essays in postfoundationalist theology, Eerdmans Publishing Company, Grand Rapids, MI.

Van Huyssteen, J.W., 2006, Alone in the World? Human uniqueness in science and theology, The Gifford Lectures, Eerdmans Publishing Company, Grand Rapids, MI.

Van Huyssteen, W., 1999, The shaping of rationality: Towards interdisciplinarity in theology and science, Eerdmans Publishing Company, Grand Rapids, MI.

Wilson, F., 2006, 'On being a father and poor in southern Africa today', in L. Richter \& R. Morrell (eds.), Baba: Men and fatherhood in South Africa, pp. 26-37, Human Science Research Council, Pretoria. 